\title{
A new high performance variable step size perturb-and-observe MPPT algorithm for photovoltaic system
}

Khadidja Saidi, Mountassar Maamoun, M'hamed Bounekhla

Department of Electronics, Faculty of Technology, University of Blida 1, Blida, Algeria

\begin{tabular}{|c|c|}
\hline Article Info & ABSTRACT \\
\hline Article history: & \multirow{6}{*}{$\begin{array}{l}\text { The optimization of energy in a photovoltaic conversion chain remains a } \\
\text { topic of study. The maximum power point tracking (MPPT) is considered the } \\
\text { most appropriate solution to ensure the extraction of the maximum power } \\
\text { which a photovoltaic generator can provide. Perturb and observe (P\&O) } \\
\text { algorithm is the well-known MPPT tracker; it shows an important and } \\
\text { decisive role in the development of photovoltaic (PV) systems. In This article } \\
\text { we introduce a new improved adjustable step size P\&O (imVS_PO) MPPT } \\
\text { method.The performances of the new algorithm are compared to the } \\
\text { conventional P\&O MPPT techniques and to the existing adjustable step size } \\
\text { P\&O (VS_PO) MPPT algorithm. The results clearly show the efficiency of } \\
\text { the improved algorithm which contributed to the increase of the tracking } \\
\text { speed with negligible fluctuations when the MPP is reached, and especially } \\
\text { in rapid variation of insolation. }\end{array}$} \\
\hline Received Dec 3, 2018 & \\
\hline Revised Feb 21, 2019 & \\
\hline Accepted Apr 28, 2019 & \\
\hline Keywords: & \\
\hline $\begin{array}{l}\text { Improved MPPT } \\
\text { Maximum power point tracking } \\
\text { perturb and observe } \\
\text { Photovoltaic system }\end{array}$ & \\
\hline
\end{tabular}

Copyright $(2019$ Institute of Advanced Engineering and Science. All rights reserved.

\section{Corresponding Author:}

Khadidja Saidi,

Department of Electronics, Faculty of Technology,

University of Blida 1, Blida, Algeria

Email: saidikhadidja@yahoo.fr

\section{INTRODUCTION}

Today, our world is fronting a severe energy crisis. As we know, most of the energy currently used is delivered by the fossil fuels such as coal, natural gas, oil or nuclear energy. Recent studies and forecasts alert us that the massive use of these resources will certainly lead to the total depletion of these reserves. In addition, everyone is convinced by the danger of these types of energy on the environment. Pollution of the environment is on a rising scale. In order to solve these problems, the focus is on renewable energy sources like photovoltaic (PV) energy which is of great importance in this regard because it is clean, inexhaustible and widely available [1].

The source of photovoltaic solar energy is the transformation using a specific sensor of solar irradiation into electrical energy known as the photovoltaic effect. The specific sensor is called photovoltaic cells. The elementary photovoltaic cell generates a very low power. To produce more power, several cells must be assembled to create a module. The construction of a high-voltage photovoltaic generator requires a series connection of the PV cells, whereas the connection of these cells in parallel increases the currentintensity. Serial/parallel wiring is therefore used to obtain a PV generator with the desired characteristics.

The current as a function as the voltage (I-V) characteristics of the photovoltaic source are not linear and have a maximum production of power output in a specific point called the maximum power point (MPP), which the efficacy-of the photovoltaic system is at its maximum [2]. Therefore, to enhance the output efficiency of PV system, it is very important to operate it near the MPP. To this end, several MPP tracking methods have been suggested and discussed in the literature [3]. These methods differ according to the oscillations around the MPP when it is reached, the complexity of the algorithm, the rate of convergence 
speed, and the cost. They are generally divided into two categories, the first one including the classical techniques [4] and the second category containing methods based on soft computing [5].

For conventional methods, the currently applied are Hill Climbing (HC) [6], Perturb and Observe (PO) [7]. Dorahaki [8], Abdulrazzaq and Ali [9] and Incremental Conductance (IC) [8], [10] which in a normal state, i.e uniform atmospheric condition, are capable to track the MPP in a fairly efficient manner and show convergence speed. But in spite of these advantages, these methods present a severe weakness that is the constant oscillation around the MPP. This oscillatory behaviour causes in significant power loss. For example, the PO technique is generally the most used because of its cost which is very low and its simplicity of implementation, but unfortunately, with this classical technique, it is impossible to satisfy at the same time a fast dynamic response with a good accuracy, this is due to the fact that the algorithm uses a fixed step size increment. When this step size increment is big, the oscillation around the maximum power point will increase during the steady state causing a loss of power, and if the step size is too low, the tracking of the MPP is not fast especially during unexpected changing of atmospheric condition [11]. The INC method is normally proposed to correct the drowbacks of the PO method. So, the oscillations at steady state can be easily eliminated. Its principle is founded as follow: the slopes of the output power curve as a function as voltage of a photovoltaic generator is greater than zero at the left of the MPP, less than zero at the right of the MPP and equal to zero at the MPP [12]. On the other hand, the zero value of the slope of the PV powervoltage curve is rarely reached for the reason of the inaccuracy of measurement.

For MPPT techniques based on soft computing (SC), we can mention those that are used most often, such as fuzzy logic methods [13 14], bio-inspired methods like artificial neural networks (ANN) technique [15, 16] and the swarm intelligence methods like Ant Colony Optimization (ACO) [17] and Particle Swarm Optimization (PSO) [18]. Regardless of their flexibility, these SC algorithms are mostly more difficult and slower than conventional methods. For illustration, artificial neural networks (ANN) techniques are used in MPPT methods and give good results in randomly changing weather conditions [16]. It is clear that the increase in the number of layers hidden in the MPPT methods based on ANN leads to an increase in the accuracy of the results, but unfortunately the computing time becomes too long without forgetting the increased complexity of the hardware implementation.

The most common swarm intelligence techniques used for the development of the MPPT controller is the optimization of ant colonization (ACO) used by the authors [17] who demonstrate by simulation a good accuracy of this method, but given the complexity of the algorithm, material realization is too difficult to perform. The PSO methods is also a swarm intelligence technique, the PSO algorithm presents a satisfactory level of covergence in the early stages, but later, this rate becomes descending, due to the fact that this algorithm depends on the initial position of agents, which leads to this low rate in some situations [19]. Given the disadvantages of traditional methods and the complexity of SC methods, research has focused on correcting the drawbacks of MPPT algorithms. The variable step size MPPT algorithm has been suggested as a solution for some techniques such as the perturb and observe method [20], the hill climbing (HC) [21] and the incremental conductance (INC) [15].

In this work, an enhanced variable step size PO (imVS_PO) MPPT algorithm is developed; the step size increment is automatically adjusted according to the MPP. Compared to the classical fixed step size or existing variable step size methods, the proposed idea can successfully improve the speed and efficiency of MPPT algorithm.

This paper consists of seven sessions which are detailed as:

Section 2 describes the photovoltaic system as well as the influence of atmospheric conditions on the PV panel. Section 3 briefly describes the principle of perturb and observe MPPT algorithm and its disadvantages when the step size increment is fixed.Section 4 presents the corrections made by using a variable step size increment in the algorithm, Section 5 illustratestheimproved VS_PO algorithm, Section 6 provides the simulation results as wel as a comparison between the improved PO MPPT algorithm and the existing VS_PO algorithm. Finally, a conclusion of this work summarizes the benefits of the improved method.

\section{PV PANEL}

A photovoltaic power of panel is a combination of cellular power; A photovoltaic cell can be assimilated to a photodiode. Figure 1 illustrates a PV cell. 


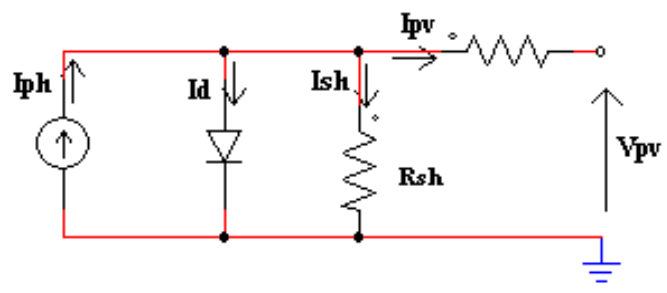

Figure 1. Simplified equivalent circuit of a photovoltaic cell.

Based on Figure 1 the output current of the solar cell is given by:

$$
I p v=I p h-I d-I s h .
$$

Where:

Iph is the current generated by the incident light, Id is the current through the diode, Ish is the current through the parallel resistor $R$ sh.

In order to increase the utilization power, the PV cells are connected in series / parallel to form a photovoltaic generator (GPV) whose equations governing it are given by:

$$
I p v=N p I p h-N p I s\left[\exp \left(\frac{q\left(V p v+\frac{N s}{N p} R I I p v\right)}{A N S K T a k}\right)-1\right]
$$

Where:

$I p v$ is the PV array output current, $I s$ is the cell reverse saturation current, $K$ is the Boltzmann constant, Tak is the temperature in degrees Kelvin, $V p v$ is the PV module output voltage, $N s$ and $\mathrm{Np}$ are the number of PV cells connected in series and in parallel respectively, $q$ is the electron charge, $A$ is the $\mathrm{p}-\mathrm{n}$ junction ideality factor, $I p h$ is given by equation 3 and $I s$ is given by equation 4 .

$$
I p h=[I s c+K i(\operatorname{Tak}-\operatorname{Tr} k)] \frac{G}{1000}
$$

Where:

$I S c$ is the cell short circuit current at reference temperature and irradiation, $K i$ is the short circuit current temperature coefficient, Trk is the cell reference temperature, $G$ is the solar irradiation in W/m2.

$$
I s=\operatorname{Irs}\left(\frac{T a k}{T r k}\right)^{3} \exp \left[\frac{q E g\left(\frac{1}{T r k}-\frac{1}{T a k}\right)}{K A}\right]
$$

Where:

Irs : Reverse saturation current at Trk, Eg : Band-gap energy of the semiconductor used in the cell [8, 9, 22].

The parameters of the PV panel (MSX60) used in our study are presented in Table 1 and the output characteristics of this PV panel resulting from the simulation by Psim software are shown in Figures 2 and 3. These figures show clearly that the output power of the photovoltaic panel has non-linear characteristic.

\begin{tabular}{cl} 
Table 1. Electrical characteristics of Solarex MSX-60 $\left(1 \mathrm{~kW} / \mathrm{m}^{2}, 25{ }^{\circ} \mathrm{C}\right)$ \\
\hline Description & MSX-60 \\
\hline Maximum power (Pm) & $60 \mathrm{~W}$ \\
Voltage Pmax(Vmpp) & $17.1 \mathrm{~V}$ \\
Current at Pmax(Impp) & $3.5 \mathrm{~A}$ \\
Short circuit current(Ish) & $3.8 \mathrm{~A}$ \\
Open circuit voltage(Voc) & $21.1 \mathrm{~V}$ \\
Temperature coeff of Voc & $-(80 \pm 10) \mathrm{mV} /{ }^{\circ} \mathrm{C}$ \\
Temperature coeff of Ish & $(0.065 \pm 0.01) \%^{\circ} \mathrm{C}$ \\
Temperature coeff of power & $(-0.50 .05) \%{ }^{\circ} \mathrm{C}$ \\
Nominal operating cell temperature & $47.2^{\circ} \mathrm{C}$ \\
\hline
\end{tabular}

Int J Pow Elec \& Dri Syst, Vol. 10, No. 3, Sep 2019 : 1662 - 1674 
Figure 2 shows that when the value of temperature is constant, the effect of the variation in solar irradiation is very high on the short-circuit current, but low on the open-circuit voltage and for Figure 3 we can show that when the solar irradiation remains constant, the open-circuit voltage changes with a variation in temperature, but the short-circuit current variation are very slow.
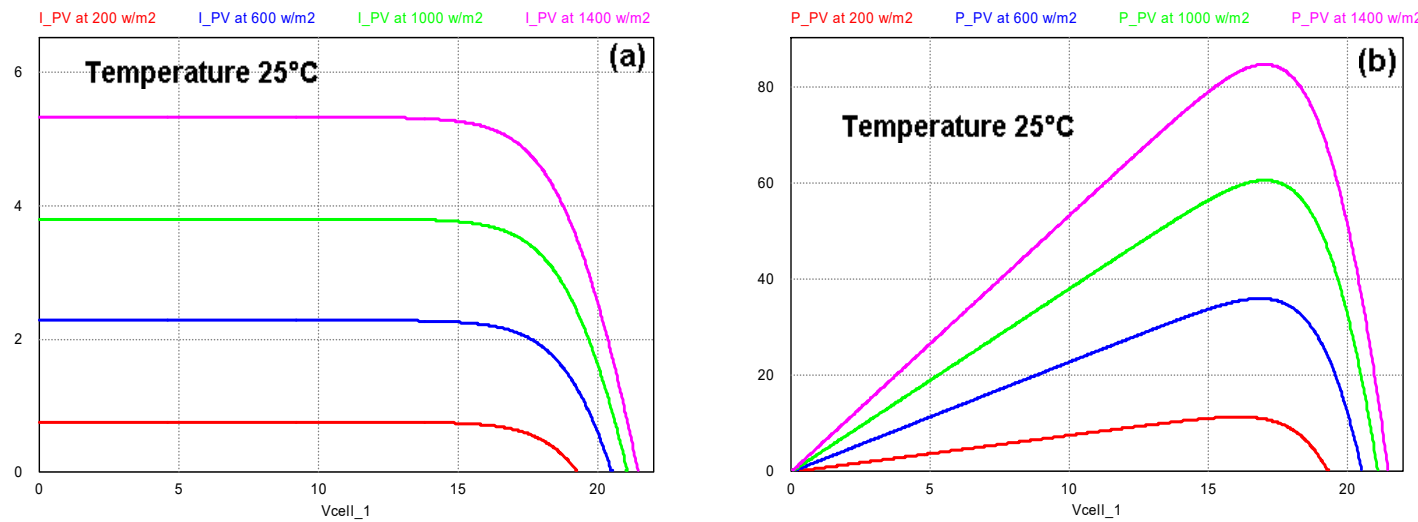

Figure 2. Characteristics of PV panel under various solar irradiance levels: (a) I_V, (b) P-V
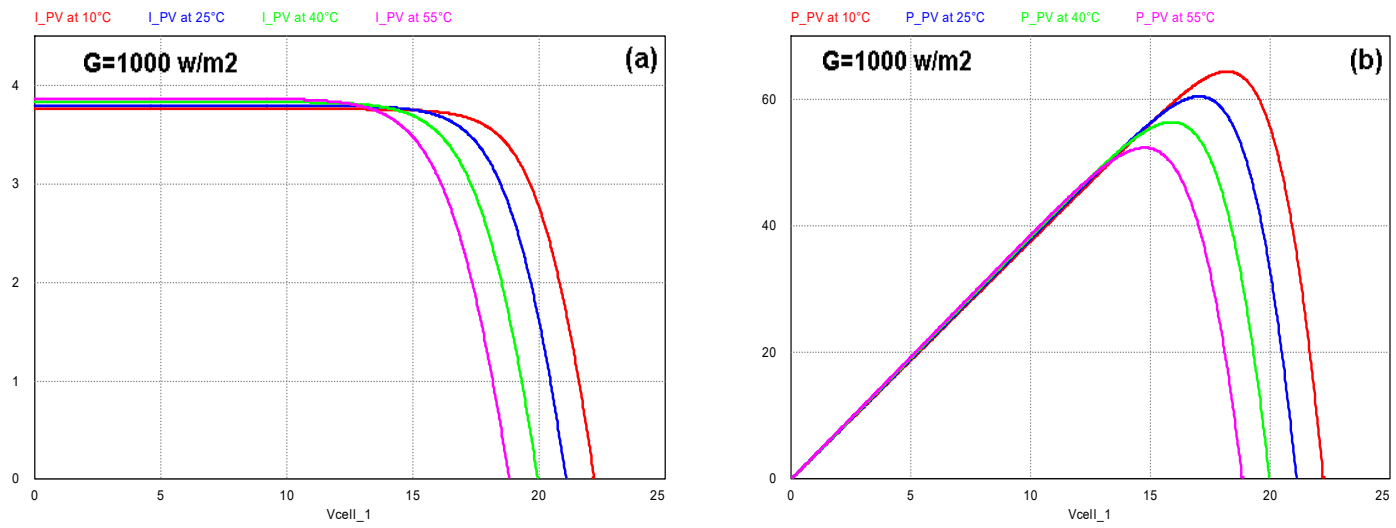

Figure 3. Characteristics of PV panel under different temperaturevalues: (a) I_V, (b) P-V

For extracting the maximum of the power from the photovoltaic module, the photovoltaic system must be functioned at its MPP, for which several MPPT methods have been developed. Conventional PO is the large amount used MPPT algorithm [23], Because of its simplicity, it is considered a standard reference used in comparisons with any new algorithm.

\section{PERTURB AND OBSERVE (PO) MPPT ALGORITHM}

The principle of the perturb-and-observe technique is based on the calculation of the output power of the photovoltaic module. The algorithm reads the voltage and the current values at the output of the PV module. After that the value of the power is calculated. The amplitude of the instantaneous output power and voltage are stored. Then after the magnitude of the current and the voltage are measured at the next time and the power is computed again from these novel values. After having power values, the decision of perturbation can be taken. When the magnitude of the power increases, the perturbation should maintain in the same direction in the following cycle, if not the direction of the perturbation will be reversed. So, the MPPT algorithm runs periodically and compares between the current value of the power and the preceding value in order to define the variation (increment or decrement) of the voltage or current of the solar panel in case of 
indirect control or the variation of the duty cycle in direct control (according to control strategy). When the MPP is achieved, the PV system fluctuates around it $[8,9,24]$. In total, three positions and two directions are involved. Figure 4 and Table 2 show and describe possible positions and directions during the perturbation and observation process, as well as the required action in each case to obtain the maximum power [20, 23].

Table 2. The PO MPPT positioning and taken action in each case

\begin{tabular}{ccc}
\hline Position & Variations & action \\
\hline 1 & 0 & No action taken \\
2 & $+\mathrm{dP} /+\mathrm{dV}$ & Increase V \\
3 & $+\mathrm{dP} /-\mathrm{dV}$ & Decrease V \\
4 & $-\mathrm{dP} /-\mathrm{dV}$ & Increase V \\
5 & $-\mathrm{dP} /+\mathrm{dV}$ & Decrease V \\
\hline
\end{tabular}

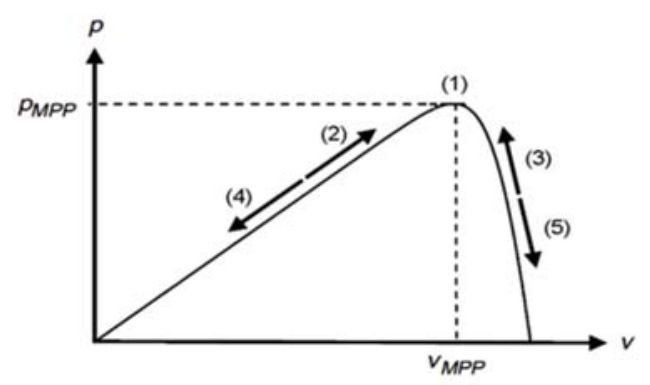

Figure 4. P\&O MPPT positionin

A flowchart of the traditional MPPT algorithm also named the fixed step size MPPT algorithm (FS_PO) is illustrated in Figure 5. The disadvantage of this method is that for small step size of the increment, the tracking is slow, but the oscillations around the MPP are weak, whereas when the step size increment is large the tracking is very fast at the cost of great oscillations.

\section{VARIABLE STEP SIZE PERTURB AND OBSERVE (VS PO) MPPT ALGORITHM}

To solve the problems of the traditional method using a fixed step size increment (large or small) it is crucial to control the photovoltaic system according to an appropriate performance. For this purpose various MPPT algorithms with variable step size increment are given and developed in the literature [25]. The principle of these algorithms is that when the operating point is distant from the MPP, the algorithm increases the size of the increment, which brings a speedy tracking of the MPP, whereas when the operating point is near the MPP, the step size increment becomes too low, consequently, the oscillation becomes very small around the MPP, which will contribute to increase of the PV system efficiency.-Figure 6 illustrates how to track the MPP using fixed and variable step size increment, and the Figure 7 shows the flowchart of VS_PO MPPT algorithm.-The variable step size adopted by [26] to reduce this problem is represented in the following equation:

$$
\text { Step }=N\left|\frac{d P}{d V}\right|
$$

Where:

$N$ is the scale factor defined in the design to regulate the step size.

So, to increase the convergence of this algorithm, the step size must satisfy the following inequality:

$$
N\left|\frac{d P}{d V}\right|<\Delta D_{\max }
$$

Where:

$\Delta D_{\max }$ is the largest allowed duty cycleperturbationof the FS_PO MPPT algorithm. Therefore it can be deduced that the scale factor can be obtained as follows:

Int J Pow Elec \& Dri Syst, Vol. 10, No. 3, Sep 2019 : 1662 - 1674 


$$
N<\Delta D_{\max } /\left|\frac{d P}{d V}\right|
$$

The (7) provides guidance for determining the scope of the scaling factor $N$. When this equation cannot be satisfied, the size of the increment takes the maximum value of the fixed step $\Delta D \max$ previously defined. So, unfortunately, the size of this method cannot guarantee the maintenance of the system in variable size mode especially when the solar irradiation is rapidly modified. Moreover, (6) shows that the $d P / d V$ is constantly compared to a constant $\left(\Delta D_{\max } / N\right.$ is constant). Then it is not possible to find an appropriate scale factor $(N)$ and a large step limiter $\left(\Delta D_{\max }\right)$ that meets the demands of the MPPT system under high irradiation changes. But, if the line $\left(\Delta D_{\max } / N\right)$ moves up and down, when the sun's radiation level changes, the abovementioned problems will disappear [27].

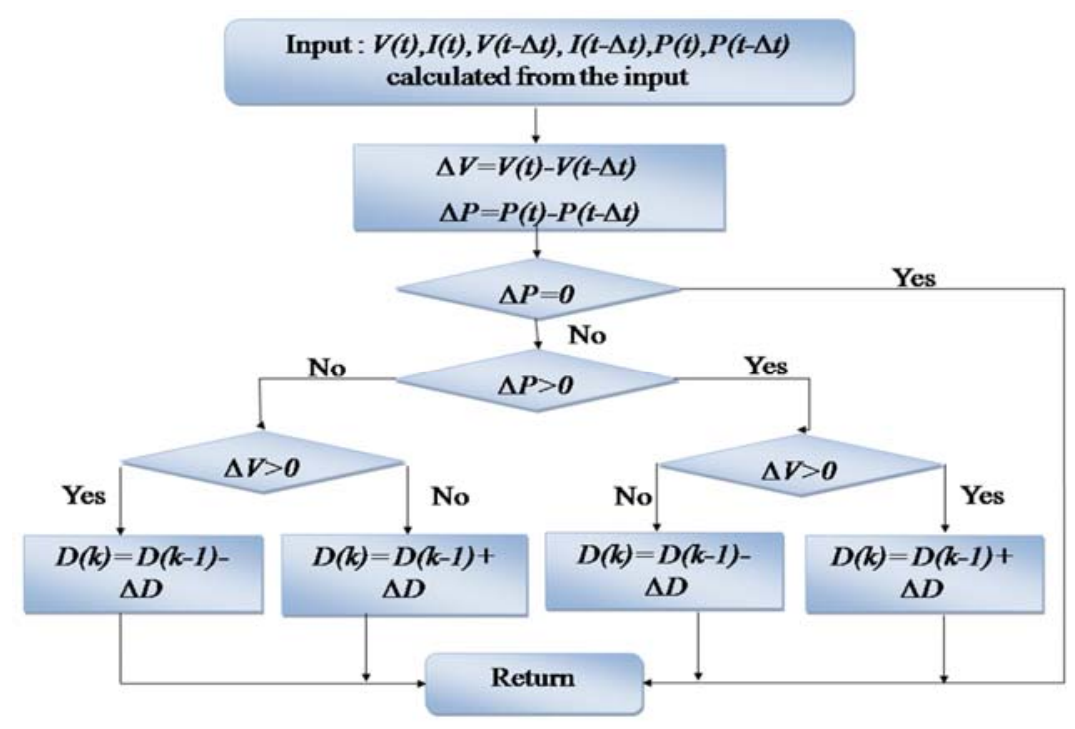

Figure 5. Flowchart of traditional PO MPPT algorithm

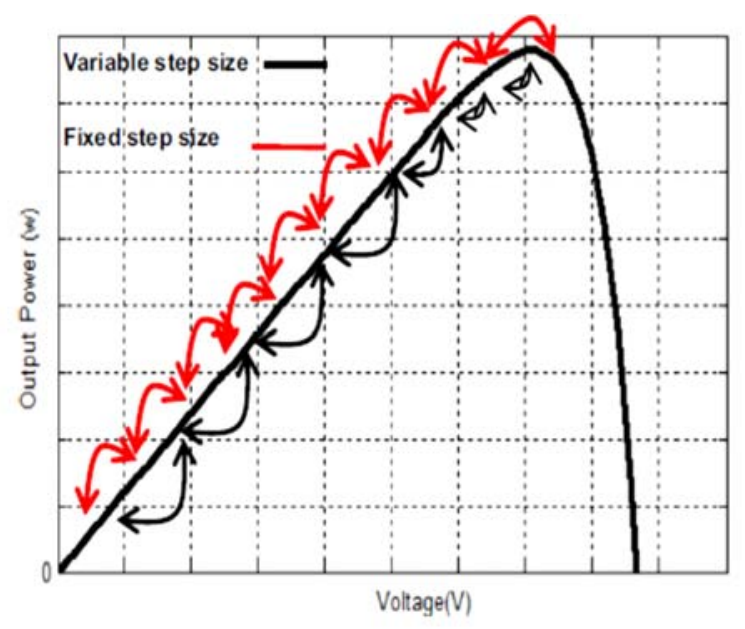

Figure 6. A manner of track of MPP with FS_PO and VS_POMPPT operation 


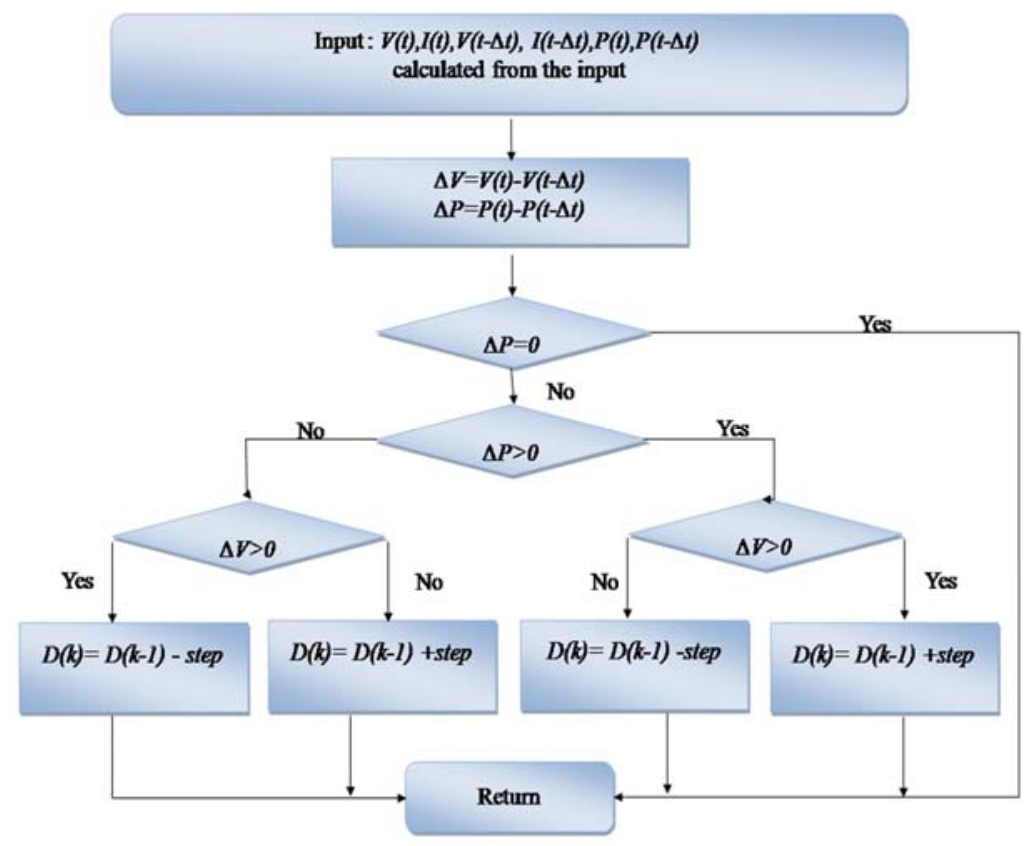

Figure 7. Flowchart of VS_PO MPPT algorithm

The solution given by [25] is that since the variation of the level of irradiation of the sun is strongly related to the output current of the photovoltaic generator, this current must be introduced in the step size increment as follows:

$$
\text { Step }=\frac{N^{\prime}}{I}\left|\frac{d P}{d V}\right|
$$

$N^{\prime}$ is the new scale factor. We can note that if the solar irradiation level increases, the current increases, and the step size of equation 8 decreases in spite of the MPPT moves away and vice versa. This note allows us to conclude that there is a lack in this equation.

\section{IMPROVED VARIABLE STEP SIZE PO (IMVS_PO) MPPT ALGORITHM}

To overcome the problem mentioned above, an improved Perturb and Observe method is proposed in this work. The new algorithm uses two different step size increments and these steps are variable. The new algorithm measured the current variation $(\Delta I)$ to determine which of these two steps (step 1 or step 2 ) is used to track the MPP. Thus, when $\Delta I$ increases, this is a consequence of the increase in the level of solar irradiation which increases the current. As a result, the step size increment increases. To do this, the (8) is multiplied by a normalization coefficient $\left(A_{1}\right)$, but if the solar irradiation level decreases, the current decreases, leading to a reduction in the step size and therefore the equation 8 is multiplied by a new coefficient $\left(A_{2}\right)$ greater than 1 . In (9) and (10) show these two proposed steps and Figure 8 shows the flowchart of the improved PO MPPT algorithm.

$$
\begin{aligned}
& \text { Step } 1=\left(\frac{N \prime}{I}\left|\frac{d P}{d V}\right|\right) A_{1} \\
& \text { Step } 2=\left(\frac{N^{\prime}}{I}\left|\frac{d P}{d V}\right|\right) A_{2}
\end{aligned}
$$

With $A_{1}<1<A_{2}$ 
This modified variable step size PO MPPT algorithm improves the dynamic response speed and steady the accuracy.

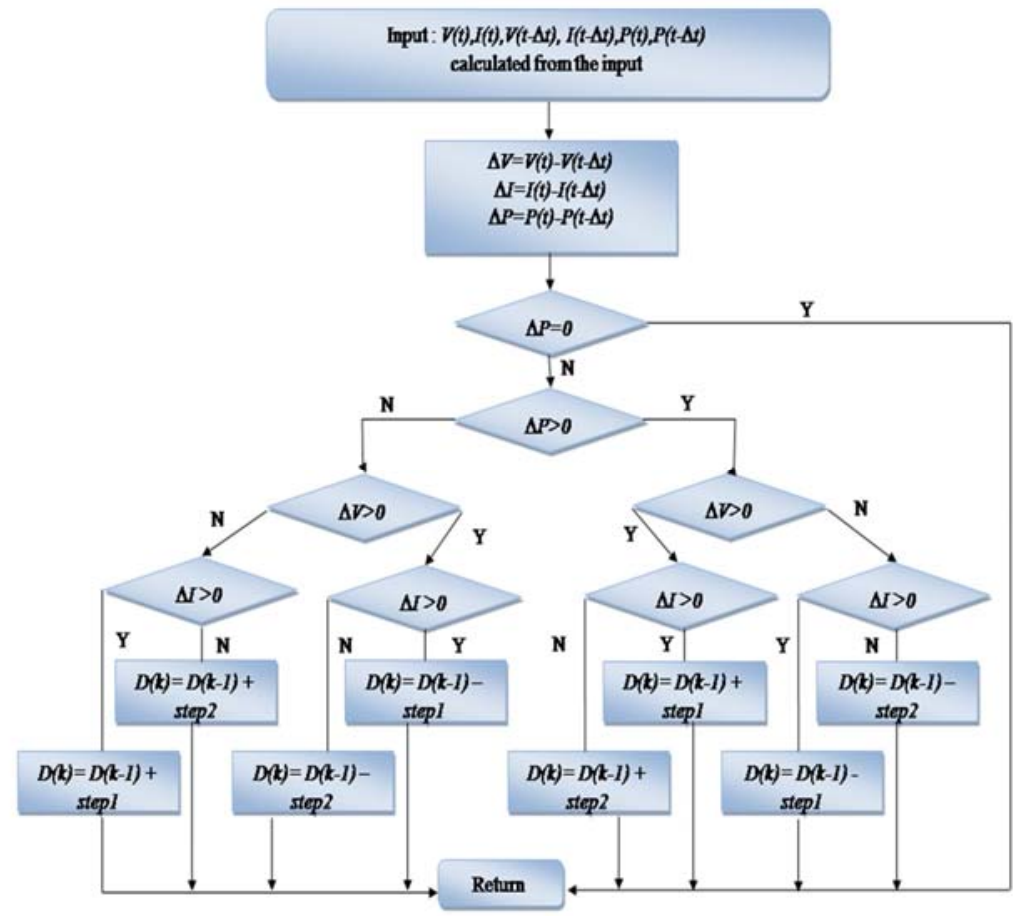

Figure 8. Flowchart of the improved VS_PO MPPT algorithm

\section{SIMULATION RESULTS}

The simulation of the existing and the improved MPPT algorithms is carried out by the Psim software and the curves are obtained. A $D C$ / $D C$ buck converter controlled by the PO MPPT algorithm is introduced in the PV system as an interface between the PV module and the load to operate the system at its MPP all the time. Figure 9 shows the different levels of solar irradiation, the output current, the output voltage and the output power of the Solarex MSX-60 PV module used in our work.

Figures 10 and 11 illustrate the output power of the photovoltaic system as a function of time for the traditional PO MPPT algorithm (FS_PO) using simultaneously a large and a small step size increment. The large step size used in this simulation is $\Delta D \max =0,07$ and the small one is $\Delta D \min =0,001$. Compared to the MPPT with small step size, the MPPT with large step size shows oscillations too high, whereas for small step size the oscillations around the MPP are negligible.

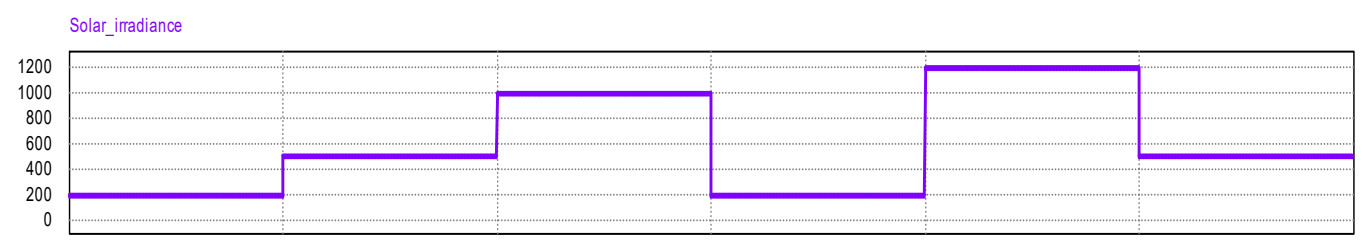

(a)

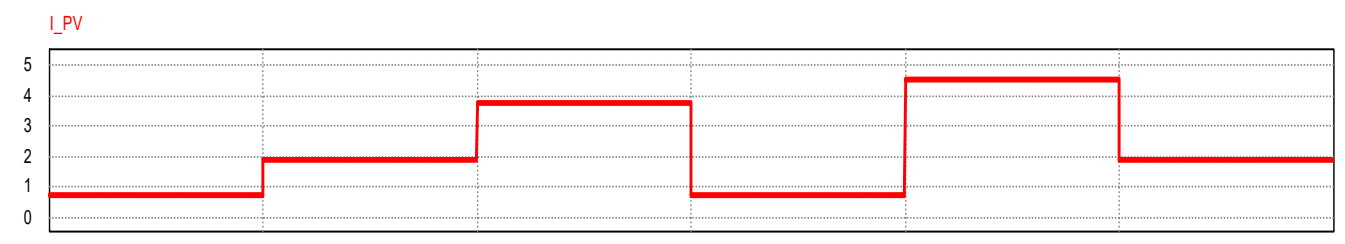

(b)

A new high performance variable step size perturb-and-observe MPPT algorithm ... (Khadidja Saidi) 


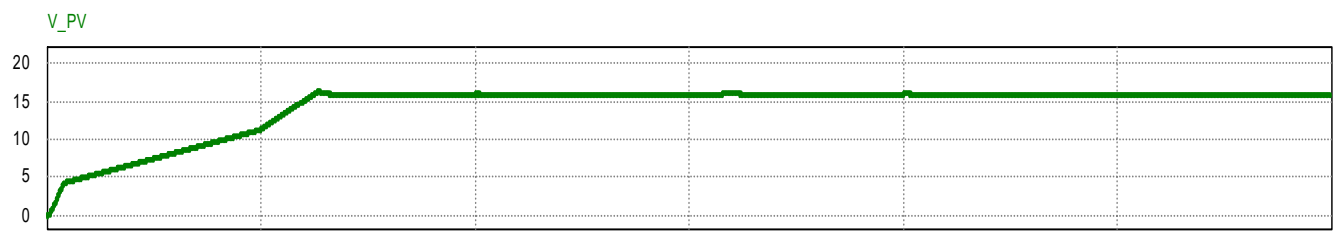

(c)

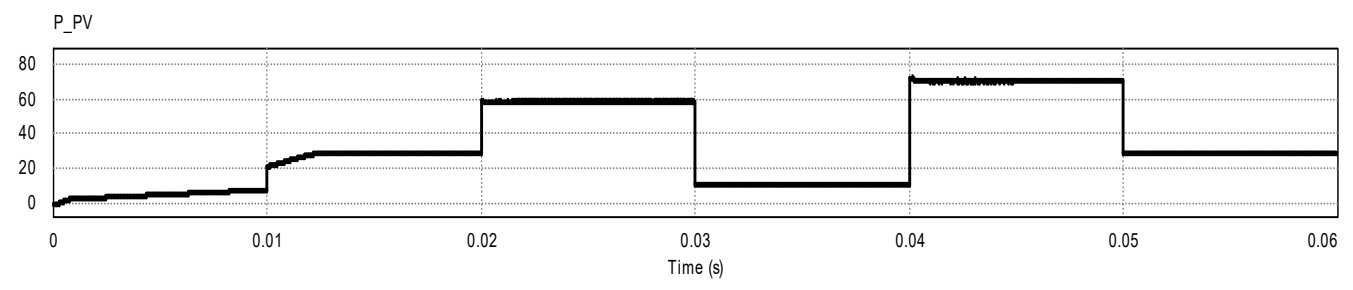

(d)

Figure 9. Simulation result: (a) Solar irradiation levels (in blue); (b). PhotovoltaicCurrent (in red); (c).Photovoltaic voltage (in dark green); (d).Photovoltaic power (in black)

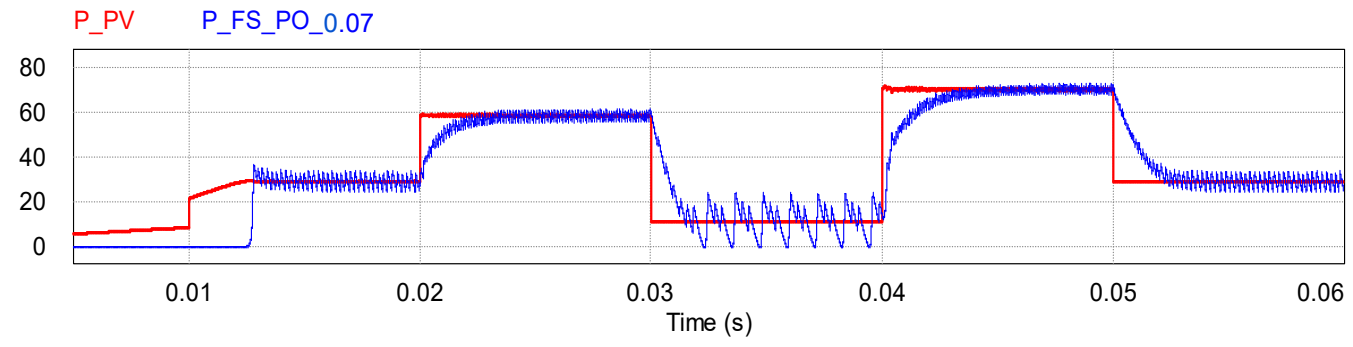

Figure 10. Comparison between output power of a photovoltaic panel (in red) and output power of PV system when we used FS_PO MPPT algorithm with large step size increment (in blue)

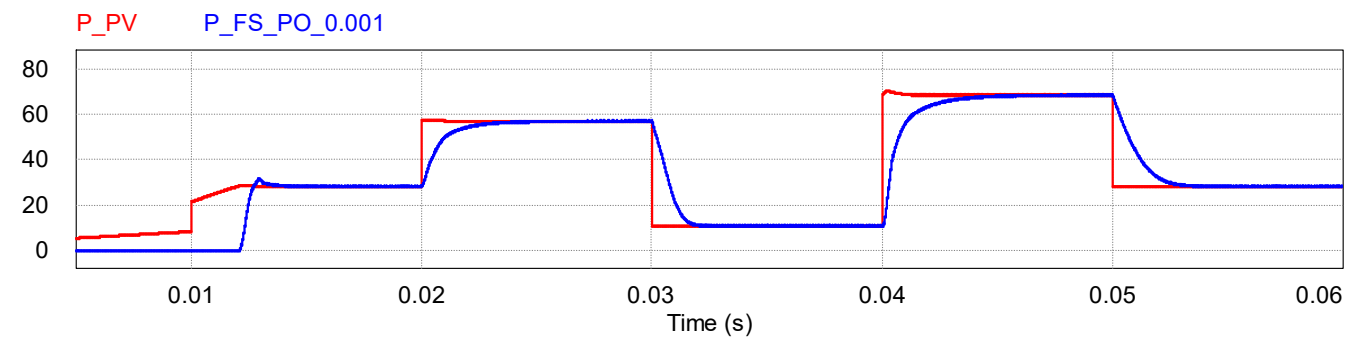

Figure 11. Comparison between output power of a photovoltaic panel (in red) and output power of PV system when we used FS_PO MPPT algorithm with small step size increment (in blue)

To prove the efficiency of the proposed VS_PO MPPT technique, a comparative study by simulation between imVS_PO, traditional FS_PO with small step size and existing VS_PO MPPT algorithms was performed. The proposed method shows several improvements in tracking accuracy, response time and overshoot.

\subsection{MPP Ttracking}

Figure 12 shows the behavior of the photovoltaic system to wards different variations of solar irradiation levels $(200,500,1000,1200$ watts / $\mathrm{m} 2)$ for the three algorithms. It may be noted that the imVS_PO algorithm has a good accuracy compared to the two other algorithms. Also we can noted that for 
sever irradiation change the improved method shows more accurate tracking compared to FS_PO and VS_PO MPPT existing algorithm.

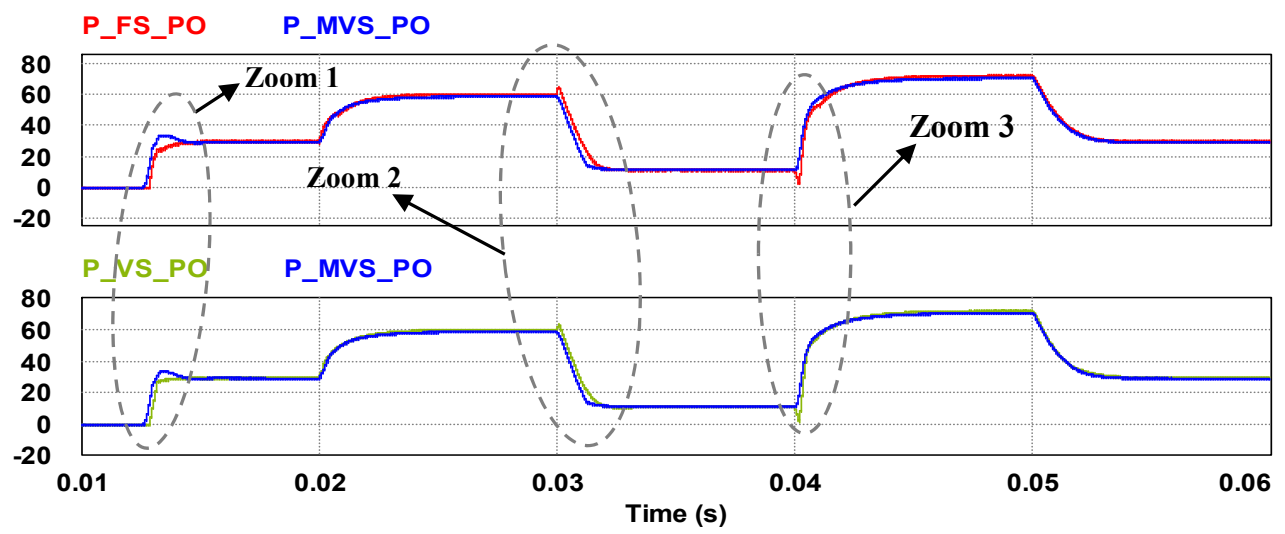

Figure 12. Comparison between output powers obtained using FS-PO MPPT algorithm and VS_PO MPPT algorithm with output power using the improved variabel step size (MVS_PO) MPPT algorithm

\subsection{Response time}

As shown in Figures 13, 14 and 15, the improved version of the VS PO MPPT algorithm clearly shows that the response time of imVS_PO algorithm is better than the FS_PO and the existing VS_PO algorithm, especially for sudden increase and decrease in solar irradiation. This will lead to a reduction in the energy loss.

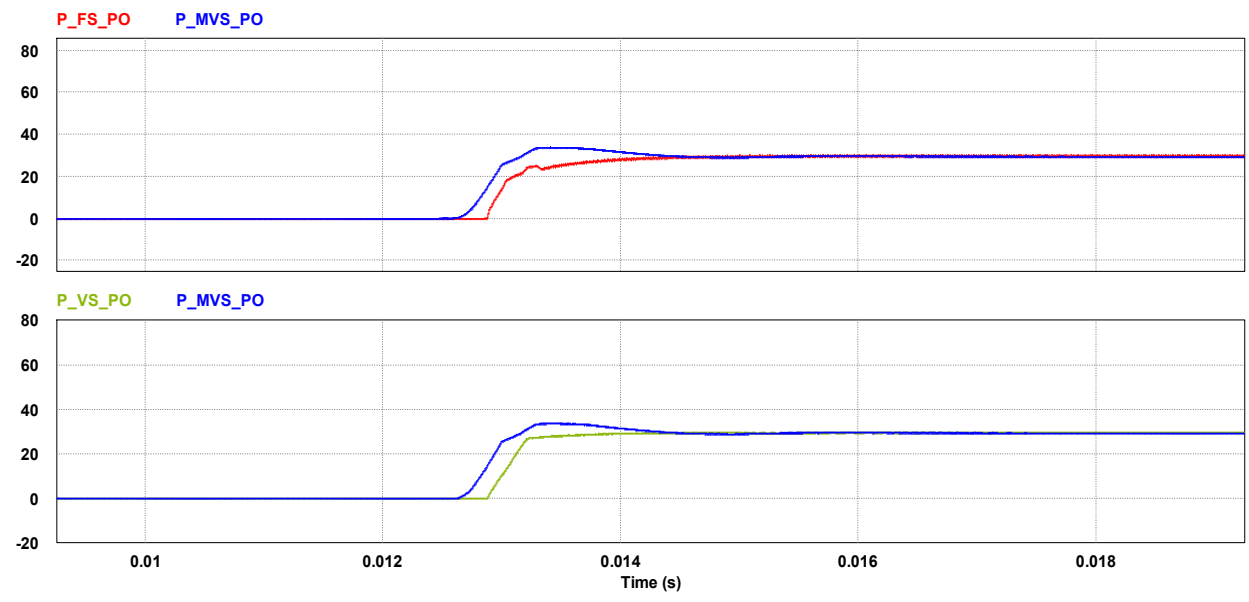

Figure 13. Zoom 1 


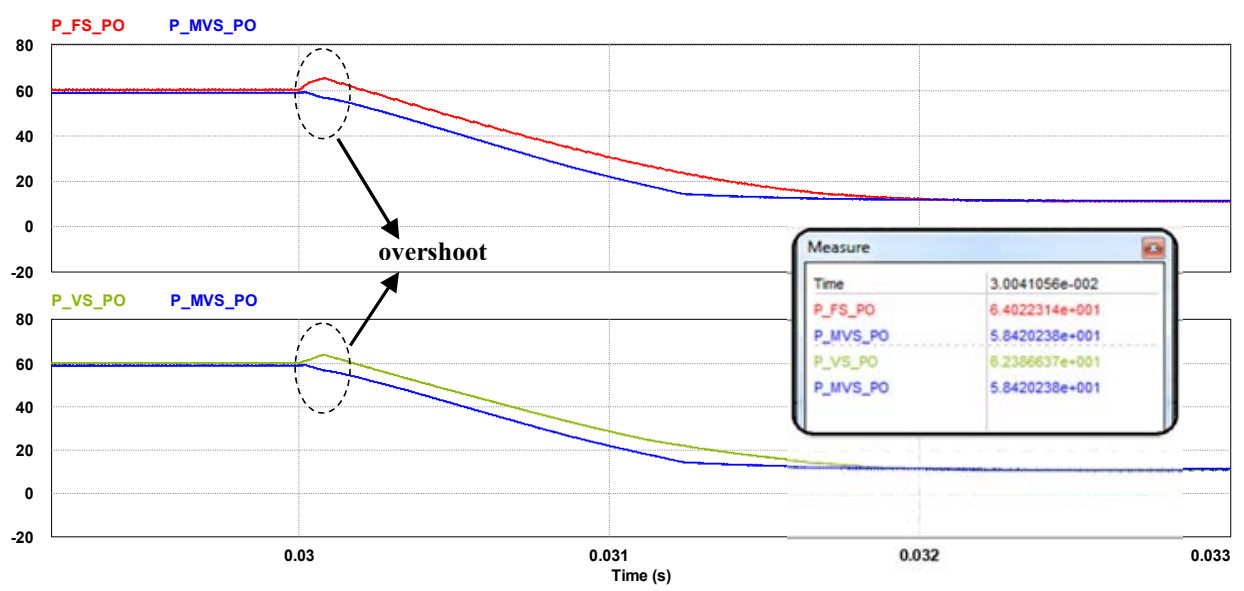

Figure 14. Zoom 2

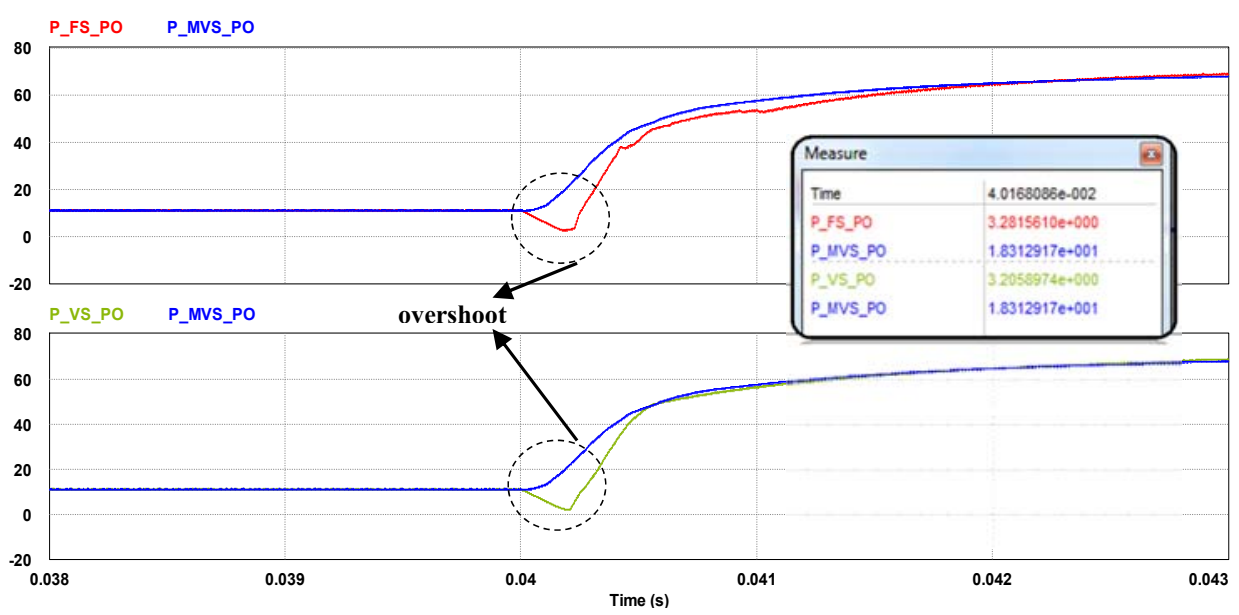

Figure 15. Zoom 3

\subsection{Overshoot}

In the Figures 14 and 15 we can see that the power curves belongs to the FS_PO MPPT method and VS_PO MPPT method show an overshoot when there is a severe change in solar radiation. We can notes that the overshoot is clearly appears from $1000 \mathrm{~W} / \mathrm{m} 2$ to $200 \mathrm{~W} / \mathrm{m} 2$ and from $200 \mathrm{~W} / \mathrm{m} 2$ to $1200 \mathrm{~W} / \mathrm{m} 2$, whereas it is less important in the case of the imVS_PO MPPT algorithm. This comparative study between the proposed variable step size, existing variable step size and fixed step size PO MPPT methods under similar operating conditions is summarized in Table 3.

Table 3. Comparison of PO MPPT methods

\begin{tabular}{ccccccc}
\hline & $\begin{array}{c}\text { MPPT traking } \\
\text { Rapidity }\end{array}$ & Response time & Overshoot & Ripple & $\begin{array}{c}\text { Steady state } \\
\text { oscillation }\end{array}$ & $\begin{array}{c}\text { Control of } \\
\text { extracted power }\end{array}$ \\
\hline FS_PO & Medium & Slow & High & Yes & Yes & Medium \\
VS_PO & Good & Medium & High & No & No & Good \\
imVS_PO & Very good & Better & No & No & No & Verry good \\
\hline
\end{tabular}

\section{CONCLUSION}

The work presented in this article concerns one of the most important problems in the optimization of energy in a PV conversion chain. Which is the track of the maximum power point, whose PO MPPT is the most famous method thanks to its simplicity and low cost. This algorithm aims a positioning of the operating 
point as close as possible to the MPP and as long as possible. To do this and to understand the properties of the MPPT control, we simulated this fixed step size PO MPPT algorithm in order to present a drawbacks of this conventional method. We have spotted severe oscillations of power around the MPP at the steady state when using a large increment step. On the other hand, the tracking is too slow in the case of using a small increment step. These results confirm the fragility of the tracking algorithm and the requirement of the improvement based on the use of variable increment step.

A comparison study, between an existing variable step size PO MPPT (VS_PO MPPT) technique and our improved version (imVS_PO MPPT), was carried out. The results show that the proposed algorithm (imVS PO MPPT) is much better than the existing VS PO MPPT algorithm, due to the optimization of the increment and its selection. This improvement not only contributed to the improvement of the performance at the steady state, but also to the speed of tracking and accuracy (no overshoot) when the weather conditions change in a severe and unexpected way. As a result, the efficacy of MPP tracking is improved and power losses have decreased which implies the improvement of the system performance.

\section{REFERENCES}

[1] J. W. Tester, M. J. Drake, Driscoll, M. W. Golay, W. A. Peters, “Sustainable Energy,” 2nd ed, Cambridge.

[2] V. Salas, E. Olias, A. Barrado, A. Lázaro, " Review of the maximum power point tracking algorithms for standalone photovoltaic systems," Solar Energy Mater.Sol. Cells, Vol. 90, No. 11, pp. 1555-1578, 2006.

[3] S. Bidyadhar, P. Raseswari, "A Comparative Study on Maximum Power Point Tracking Techniques for Photovoltaic Power Systems,” IEEE Transactions On Sustainable Energy, Vol. 4, No. 1, pp. 89-98, 2013.

[4] T. Esram, P.L. Chapman, "Comparison of photovoltaic array maximum power point tracking techniques," IEEE Trans. Energy Convers, Vol. 22, No. 2, pp. 439-449, 2007.

[5] Z. Salam, J. Ahmed, B.S. Merugu, "The application of soft computing methods for MPPT of PV system: a technological and status review," Appl Energy, Vol. 107, pp. 135-148, 2013.

[6] X. Weidong, W. G. Dunford, "A modified adaptive hill climbing MPPT method for photovoltaic power systems," IEEE Power Electron Spec Conf, Vol. 35, pp. 1957-196, 2004.

[7] N. Femia, G. Petrone, G. Spagnuolo, M. Vitelli, "Optimization of perturb and observe maximum power point tracking method," Power Electron, IEEE Transaction, Vol. 20, pp. 963-973, 2005.

[8] S. Dorahaki, "A Survey on Maximum Power Point Tracking Methods in Photovoltaic Power Systems," Bulletin of Electrical Engineering and Informatics, Vol. 4, No. 3, pp. 169-175, 2015.

[9] A. Abdulwahhab Abdulrazzaq, A. Hussein Ali, "Efficiency Performances of Two MPPT Algorithms for PV System with Different Solar Panels Irradiances," International Journal of Power Electronics and Drive System (IJPEDS), Vol. 9, No. 4, pp. 1755-1764, 2018.

[10] C.H.Lin, C.H. Huang, Y.C. Du, J.L. Chen, "Maximum photovoltaic power tracking for the PV array using the fractional order incremental conductance method," Applied Energy, Vol. 88, pp. 4840-4847, 2011.

[11] M. Quamruzzaman, K. M. Rahman, "A Modified Perturb and Observe Maximum Power Point Tracking Technique for Single-Stage Grid-Connected Photovoltaic Inverter," WSEAS Transactions on power systems, Vol. 9, pp. 111-118, 2014.

[12] F. Liu, S. Duan, B. Liu, F. Y. Kang, "A variable step size INC MPPT method for PV systems," IEEE trans on Industrial Electronics, Vol. 55, No. 7, pp. 2622-2628, 2008.

[13] A. Saudi Samosir, H. Gusmedi, S. Purwiyanti, E. Komalasari , "Modeling and Simulation of Fuzzy Logic based Maximum Power Point Tracking (MPPT) for PV Application," International Journal of Electrical and Computer Engineering (IJECE), Vol. 8, No. 3, pp. 1315-1323, 2018.

[14] D. M. Atia, H. T. El-madany, "VHDL Based Maximum Power Point Tracking of Photovoltaic Using Fuzzy Logic Control," International Journal of Electrical and Computer Engineering (IJECE), Vol. 7, No. 6, pp. 3454-3466, 2017.

[15] S. Assahout, H. Elaissaoui, A. El Ougli, B. Tidhaf, H. Zrouri , "A Neural Network and Fuzzy Logic based MPPT Algorithm for Photovoltaic Pumping System", International Journal of Power Electronics and Drive System (IJPEDS), Vol. 9, No. 4, pp. 1823-1833, 2018.

[16] M. Veerachary, N. Yadaiah, "ANN based peak power tracking for PV supplied DC motors," Solar Energy, Vol. 69, pp. 343-350, 2000.

[17] L.L. Jiang, D.L. Maskell, J.C. Patra, "A novel ant colony optimization-based max-imum power point tracking for photovoltaic systems under partially shaded conditions," Energy Build, Vol. 58, pp. 227-236, 2013.

[18] K. Ishaque, Z. Salam, M. Amjad, S. Mekhilef, "An improved particle swarm optimization (PSO)-based MPPT for PV with reduced steady-state oscillation,” Power Electron, IEEE Trans, Vol. 27, pp. 3627-3638, 2012.

[19] L. Hwa, H.Shyh-Ching, H. Jia-Wei, L. Wen-Cheng, "A particle swarm optimization-based maximum power point tracking algorithm for PV systemsoperating under partially shaded conditions," IEEE Trans. Energy Convers, Vol. 27, pp. 1027-1035, 2012.

[20] L. Piegari, R. Rizzo, "Adaptive perturb and observe algorithm for photovoltaic maximum power point tracking," IET Renewable Power Generation, Vol. 4, No. 4, pp. 317-328, 2010.

[21] W. Xiao, W.G. Dunford, "A modified adaptive hill climbing MPPT method for photovoltaic power systems," Proc. PESC, pp. 1957-1963, 2004. 
[22] A. Jubaer, S. Zainal, "A Maximum Power Point Tracking (MPPT) for PV system using Cuckoo Search with partial shading capability," Applied Energy, Vol. 119, pp. 118-130, 2014.

[23] N. Fermia, D. Granozio, G. Petrone, M. Vitelli, "Predictive \& adaptive MPPT perturb and observe method," Aerospace Electron Syst, IEEE Trans, Vol. 43, pp. 934-950, 2007.

[24] S. Gomathy, S. Saravanan, S. Thangavel, "Design and implementation of Maximum Power Point Tracking (MPPT) algorithm for a standalone PV system," Elixir Elec. Engg, Vol. 51A, pp. 11110-11114, 2012.

[25] A.I. Behzad,A. Parviz, " Improved variable step size incremental conductance mppt method with high convergence speed for pv systems," Journal of Engineering Science and Technology, Vol. 11, No. 4, pp. 516 -528, 2016.

[26] P. Sivaraman, A. Nirmalkumar, "A new method of maximum power point tracking for maximizing the power generation from an SPV plant," Journal of scientific \& industrial research, Vol. 74, pp. 411-415, 2015.

[27] L. Chendi, C. Yuanrui, Z. Dongbao, L. Junfeng, Z. Jun, "A High-Performance Adaptive Incremental Conductance MPPT Algorithm for Photovoltaic Systems,” Energies, Vol. 9, pp. 288-317, 2016.

Int J Pow Elec \& Dri Syst, Vol. 10, No. 3, Sep 2019 : 1662 - 1674 